\title{
PHOBIAS, OTHER PSYCHIATRIC COMORBIDITIES AND CHRONIC MIGRAINE
}

\author{
Felipe Corchs ${ }^{1,2}$, Juliane P.P. Mercante ${ }^{1,2}$, Vera Z. Guendler ${ }^{1}$, \\ Domingos S. Vieira 1,3, Marcelo R. Masruha 1,3, Frederico R. Moreira', \\ Marcio Bernik2, Eliova Zukerman', Mario F.P. Peres ${ }^{1,3}$
}

\begin{abstract}
Background: Comorbidity of chronic migraine (CM) with psychiatric disorders, mostly anxiety and mood disorders, is a well-recognized phenomenon. Phobias are one of the most common anxiety diso rders in the general population. Phobias are more common in migraineurs than non-migraineurs. The clinical profile of phobias in CM has never been studied. Method: We investigated the psychiatric profile in 56 patients with CM using the SCID I/P interview. Results: Lifetime criteria for at least one mental disorder was found in $87.5 \%$ of the sample; $75 \%$ met criteria for at least one lifetime anxiety disorder and $60.7 \%$ of our sample fulfilled DSM-IV criteria for lifetime phobic avoidant disorders. Mood and anxiety sc o reswere higher in phobic patients than in non-phobic CM controls. Number of phobias correlated with higher levels of anxiety and depression. Conclusion: Phobias are common in CM. Its recognition may influence its management. Early treatment may lead to better prognosis.
\end{abstract}

KEY WORDS: headache, migraine, anxiety, phobias.

\begin{abstract}
Fobias, outras comorbidades psiquiátricas e enxaqueca crônica
RESUMO - Intrølução: As comorbidades psiquiátricas das enxaquecas crônicas são bem conhecidas. As fobias, transtorno ansioso mais comum, são mais prevalentes entre enxaquecosos do que entre não enxaquecosos. O perfil clínico de fobias em uma população enxaquecosa nunca foi estudado. Método: Estudamos aspectos psiquiátricos de uma população de 56 pacientes com enxaqueca crônica. Resultados: Usando o SCID I/P para o DSM-IV, critérios diagnósticos para ao menos algum transtorno psiquiátrico durante a vida foram preenchidos por $87,5 \%$ de nossa amostra, $75 \%$ para ao menos um transtorno ansioso e $60,7 \%$ para condições fóbicas em algum momento de suas vidas. Os escores de ansiedade e humor foram maiores entre os fóbicos e o número de fobias teve correlação positiva com o grau de ansiedade e depressão. Conclusão: Fobias são comuns na enxaqueca crônica e seu reconhecimento poderia influenciar seu manejo e melhorar seu prognóstico.
\end{abstract}

PALAVRAS-CHAVE: cefaléia, enxaqueca, ansiedade, fobia.

The importance of psychiatric comorbidity in migraine has long been recognized ${ }^{1,2}$. There is a growing body of evidences that they may share diverse epidemiological, pathophysiology, and treatment response aspects ${ }^{3}$. Among psychiatric comorbidities, those with mood and anxiety disorders are the most common. Anxiety disorders are common in episodic migraine patients but even more frequent in chronic migraineurs ${ }^{4}$. Somatic complains are common among anxious subjects, mostly tachycardia, dyspnea, gastrointestinal discomfort, and muscular pain. Headaches can also be part of these unspecific somatic manifestations. On the other hand, migraine and anxiety may be more closely related than just unspe- cific somatic complains ${ }^{5,6}$. Merikangas et al. ${ }^{5}$, in a prospective study, found anxiety disorders to be more frequently comorbid with migraine than affective di so rders. They also suggest that migraine with anxiety and depression may constitute a distinct syn$\mathrm{d}$ rome comprising anxiety, the primary phenomena, often manifested in early childhood, and followed by the occurrence of migraine headaches, and then by discrete episodes of depressive disorder in latter adulthood. In other study, phobias in adolescents and young adults were outstanding predictors of latter, incident migraines? ${ }^{7}$.

Anxiety disorders also greatly increase the use of medical resources in migraine patients, with higher

${ }^{1}$ Instituto Israelita de Ensino e Pesquisa Albert Einstein, São Paulo SP, Brazil; ${ }^{2}$ AMBAN, Instituto de Psiquiatria da FMUSP, São Paulo SP, Brazil; ${ }^{3}$ Neurociências, Universidade Federal de São Paulo, São Paulo SP, Brazil.

Received 10 April 2006, received in final form 13 July 2006. Accepted 28 August 2006.

Dr. Mario Fernando Prieto Peres - Alameda Joaquim Eugenio de Lima 881 / 708 - 01403-001 São Paulo SP - Brasil. E-mail: marioperes@yahoo.com 
annual direct costs $(12,642 \text { US } \$ \text { vs } 5,179 \text { US } \$)^{8}$ in the United States of America. In addition, anxiety disorders creates additional decreases in quality of life levels in chronic migraine patients ${ }^{9}$. According to the DSM-IV ${ }^{10}$, anxiety disorders encompass several conditions including: generalized anxiety disorder (GAD), panic disorder (PD) and agoraphobia, posttraumatic stress disorder (PTSD), social phobia (SP), specific phobia, obsessive-compulsive disorder (OCD) and the less clearly defined mixed anxiety-depressive disorder. Phobias are the most common anxiety disorder in the general population, the lifetime prevalence has been found to be up to $12.5 \%$ in specific phobias and $13.0 \%$ in social phobia, which is one of the most common psychiatric condition ${ }^{11-13}$; up to $23 \%$ if child life simple phobias are included. Phobias are more common in migraineurs than non-migraineurs; the clinical profile of phobias in CM has never been studied.

In this paper we re porton a systematic investigation on the clinical aspects of the comorbidity of phobias in CM patients and their relationship with other psychiatric comorbidity.

\section{METHOD}

Fifty-six patients with $\mathrm{CM}$ according to the International Headache Society criteria (IHS) ${ }^{14}$ were selected for this study ( 51 women, 5 men, aged 24 to $64 \mathrm{y}$. mean \pm sd $41.69 \pm 11.71$ ). Ch ronic users of acute migraine medication that did not fulfill criteria for medication overuse headache (MOE) were also included in the study. Doubtful cases were excluded.

Headache disability was measured by the Migraine Disability Assessment (MIDAS) ${ }^{15}$, a 0 to 100 visual analogue

Table 1. Detailed description of phobias according to specific class and severity.

\begin{tabular}{lclc}
\hline Class of phobia & $\mathrm{N}(\%)$ & Severity & $\mathrm{N}$ \\
\hline Specific* & $20(58.8)$ & Mild & 9 \\
& & Moderate & 10 \\
& & Severe & 1 \\
Social & $15(44.1)$ & Mild & 8 \\
& & Moderate & 8 \\
& & Severe & - \\
Agoraphobia & $2(5.9)$ & Mild & - \\
& & Moderate & 2 \\
Total & $34(100)$ & Severe & - \\
\hline
\end{tabular}

* Eight phobias of animal, nine of natural environment, five of injection, two of blood and two non-specified. Note - The values in the lines "total" and "specific" are referred to the number of patients that fulfill criteria for at list one phobic diagnostic and at list one specific phobiarespectively. Notice that there may be some patients that have more than one type of phobia. impact scale ( 0 meaning the highest impact and 100 no impact) assessing the amount of disability caused by headaches along the month (global) and during the attack. Total headache frequency was also ascertained.

Psychic profile was assessed by the SCID 1/P ${ }^{16}$, a stru ctu red interview for psychiatric disorders based on the DSMIV diagnostic criteria ${ }^{10}$, and applied by a trained clinician. We further evaluated intensity of depressive symptoms with the Hamilton depression rating scale (HAM-D) ${ }^{17}$ and the Beck depression inventory (BDI) ${ }^{18}$. The intensity of anxiety symptoms was assessed by the Hamilton rating scale for anxiety (HAM-A) ${ }^{19}$ and the Spielberger state-trait anxiety inventory (STAI) ${ }^{20}$.

The re se a rch protocol was reviewed and approved by the Hospital Israelita Albert Einstein Committee of Ethic in Research. All subjects signed written consent form s prior to assessment.

Statistical analyses were perf o rmed to investigate possible diffe rences in headache characteristics and in anxiety/ depression scores in patients with phobias versus those without phobias. The number of patients with a mood diso rder (major depressive episode and/or dysthymia) was calculated in those with and without phobias. The anxiety and depression levels were also compared.

The Fisher's exact and the Student's T-test were used for the analysis. Results were considered significant when $P<.05$ but trends of $P<.10$ were also reported. All tests were two tailed. Data were processed with the statistical package SPSS 10.0 for windows (SPSS, Chicago, Illinois).

\section{RESULTS}

Forty-nine patients $(87.5 \%)$ of our sample met criteria for at least one lifetime mental disorder. Sixteen subjects (28.6\%) fulfilled criteria for major depressive disorder, one for dysthymia, 2 for bipolar disorder and 3 for grief. Two patients met criteria for an eating disorder and 4 for alcohol and/or non-alcoholic substance use disorders. Forty-two subjects (75\%) of our sample presented at least one lifetime anxiety disorder. Twenty-five subjects (44.6\%) fulfilled criteria for GAD, one for PD, one for OCD, and 3 cases for PTSD. The phobic conditions are fully described in results.

Thirty-four patients $(60.7 \%)$ of our sample fulfilled DSM-IV diagnostic criteria for a phobic anxious condition (social, specific, or agoraphobia) in their lifespan. At the moment of the evaluation, 20 (35.7\%) patients had a diagnosis of specific phobia, $15(26.8 \%)$ social phobia, and 2 agoraphobia. Four patients had a history of phobic conditions in the past but did not fulfilled criteria for these conditions at the moment of the evaluation (one specific, one social and two agoraphobia). Details upon prevalence, type and severity of phobias are presented on Table 1.

Interactions among phobias, mood disorders, and non-phobic anxiety disorders, proved to be complex 
Table 2. Comparison of migraine severity and psychopathology between phobic and non-phobic patients.

\begin{tabular}{|c|c|c|c|c|c|}
\hline \multicolumn{3}{|c|}{ Migraine severity } & \multicolumn{3}{|c|}{ Psychopathology } \\
\hline & \multicolumn{2}{|c|}{ Mean \pm standard deviation } & & \multicolumn{2}{|c|}{ Mean \pm standard deviation } \\
\hline & Phobic & Non-phobic & & Phobic & Non-phobic \\
\hline Total frequency & $25.93 \pm 5.01$ & $26.38 \pm 4.85$ & STAI - trait** & $46.70 \pm 9.80$ & $42.00 \pm 9.52$ \\
\hline MIDAS & $69.03 \pm 69.30$ & $92.50 \pm 90.45$ & STAI - state** & $50.20 \pm 11.33$ & $43.86 \pm 12.18$ \\
\hline $0-100$ & $51.81 \pm 25.68$ & $49.00 \pm 26.39$ & $\mathrm{BDI}$ * & $15.13 \pm 9.22$ & $9.95 \pm 7.36$ \\
\hline \multirow[t]{2}{*}{ Global impact } & $39.93 \pm 16.18$ & $35.48 \pm 20.43$ & HAM-A* & $18.97 \pm 6.86$ & $15.14 \pm 6.36$ \\
\hline & & & HAM-D* & $20.74 \pm 8.63$ & $13.45 \pm 7.61$ \\
\hline
\end{tabular}

${ }^{*} p<05 ;{ }^{* *} .05<p<.1$

with high levels of comorbidity. These interactions can be well visualized in the Venn's diagram below (Fig 1).

When phobic patients are compared with nonphobic patients, headache severity levels did not differ between the groups (Table 2) even though diffe rences were found on severity of psychiatric symptoms (BDI, HAM-A and HAM-D or a trend in IDATE). Some patients fulfilled criteria for more than one kind of phobia, a variable that seem to exert influence on psychopathology as illustrated on Figure 2.

\section{DISCUSSION}

Despite of the importance of phobic disorders and the avoidant behaviour characteristic of phobic-anxious conditions, among psychiatric comorbidities observed in migraneurs, very little was studied about this issue. One study evaluated the personality of patients with headaches, demonstrating that patients with migraine and tension type headache scored higher on harm avoidance factor of personality than did controls $\mathrm{s}^{21}$, even though this finding was not con$\mathrm{fi}$ rmed by other authors ${ }^{22}$. According to Cloninger's theor ${ }^{23}$, harm avoidance would be a heritable temperament trait related to inhibition of behaviours, such as pessimistic worry and passive avoidance behaviours, such as fear of uncertainty and shyness.

Radat et al. ${ }^{24}$ pointed a greater incidence of psychiatric disorders among migraneous patients that $\mathrm{ch}$ ronically used substances compared with patients without that history. In this study, two of the three most frequent diagnosis observed were anxious conditions and the other one was major depressive disorder, which was frequently accompanied by anxiety symptoms, such as fear and avoidant behavior. In a prospective evaluation of this cohort, the authors found important longitudinal comorbidity between anxious disorders and migraine. However, in logistic

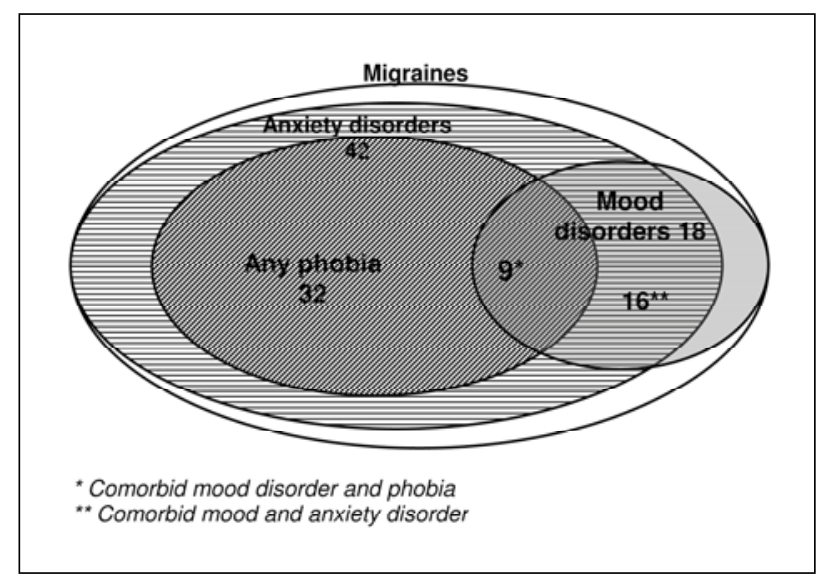

Fig 1. Venn diagram showing the interaction of psychiatric comorbid disorders in chronic migraine patients.

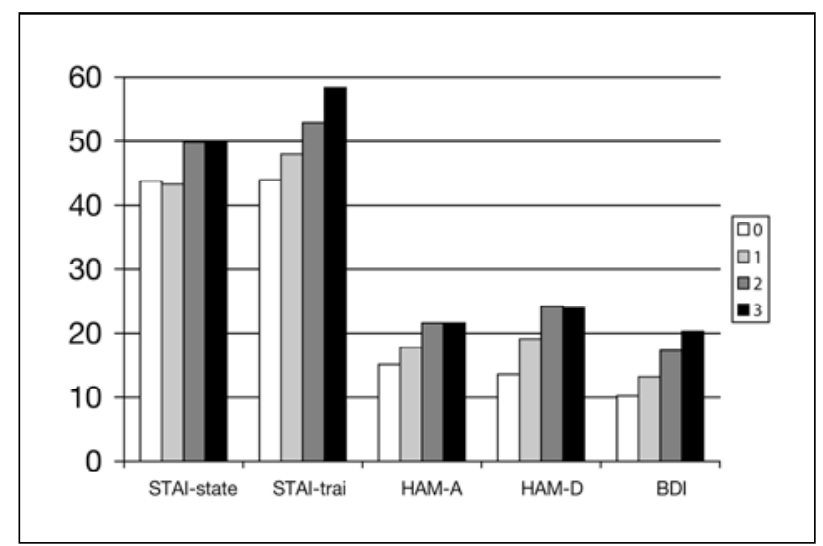

Fig 2. Mean psychiatric scales for patients with $0,1,2$, or 3 phobias.

reg ression models including age, sex, and psychiatric illness in 1981, only phobia was predictive of future migraine ${ }^{7}$.

The present study provides more insight into the understanding of a yet unexplored matter on migrai- 
ne field: the phobic-anxious aspects. A trend, a phobic-anxious trait of personality, or a psychiatric (anxiety) disorder might play a role in the process of migraine chronification. A comparison, for example, of the rates of specific phobias in our sample $(31.82 \%)$ with the prevalence of phobias in the general population $(12.5 \%)^{11-13}$, seems to show a trend of higher levels of phobias in CM then in the population as a whole.

A preliminary understanding of this relationship is provided by behavioral theories. A core feature of phobic-avoidant disorders is the anticipatory anxiety, a state of preparation for an imminent or likely th reat. Subjects with a high level of trait anxiety tend to be more sensitive to potential threats or to the aversive nature of anticipatory anxiety. These subjects may develop avoidant behaviors to keep them away from those stimuli or aversive emotional states. This could explain, at least in part, why some patients take hold of analgesics in the least warning of pain. If so, we could be looking for a sub-group of CM patients with poorer prognosis, making their headaches worse by overusing acute medication. Fear of having a headache attack or worsening a baseline headache in daily suffe erers may start a behavior of analgesic intake or decrease the threshold of analgesic utilization ${ }^{25}$.

It must be clear, however, that definitive conclusions about the role of phobias in favoring chronicity and/or overuse could be drawn only by directly comparing frequency of headache with the use of acute migraine medication. In spite of the design of the present study do not allow this direct conclusion, we can observe that the more phobias patients present, the higher the levels of anxiety and depression in CM patients. It has been recognized that they deserve special psychiatric attention, but a focus on phobic aspects may influence its management and eventually treatment response. Although there is a lack of evidence to support any recommendations when phobias and migraines are related, it is clear that treating the phobic condition is a key point as to avoid the overuse of analgesics. Psychological interventions may be outstanding on the maintenance of the abstinence of analgesics. Treatment of phobias in CM may lead to lower level of anxiety and depression and a better quality of life.

\section{REFERENCES}

1. Cobb S, Miles HH. Psychiatric conference: migraine and character neurosis. Am Pract Diag Treat 1952;3:985-990.

2. Mercante JPP, Peres MFP, Guendler V, Zukerman E, Bernik, M. Depression in chronic migraine: severity and clinical features. A rq Neuropsiquiatr 2005;63:217-220.

3. Radat F, Swendsen J. Psychiatric comorbidity in migraine: a review. Cephalalgia 2005;25:165-178.

4. Scher AI, Bigal ME, Lipton RB. Comorbidity of migraine. Curr Opin Neurol 2005;18:305-310.

5. Merikangas KR, Angst J, Isler H. Migraine and psychopathology: results of the Zurich cohort study of young adults. Arch Gen Psychiatry 1990; 47:849-853.

6. B reslau N, Davis GC, Andreski P. Migraine, psychiatric disorders, and suicide attempts: an epidemiologic study of young adults. Psychiatry Res 1991;37:11-23.

7. Swartz KL, Pratt LA, Armenian HK, Lee LC, Eaton WW. Mental diso rders and the incidence of migraine headaches in a community sample: results from the Baltimore Epidemiologic Catchment area followup study. Arch Gen Psychiatry 2000;57:945-950.

8. Pesa J, Lage MJ. The medical costs of migraine and comorbid anxiety and depression. Headache 2004;44:562-570.

9. Mercante JPP, Peres MFP, Guendler VZ, Corchs F, Bernik MA, Zukerman E. Impact of psychiatric comorbidity in the quality of live of chronic migraine patients. Migrâneas e Cefaléias 2005;8:76.

10. American Psychiatric Association. Diagnostic and statistical manual of mental disorders, $4^{\text {th }}$ ed. Washington: American Psychiatric Association 1994.

11. Kessler RC, McGonagle KA, Zhao S, et al. Lifetime and 12-month prevalence of DSM-III-R psychiatric disorders in the United States: results from the National Comorbidity Survey. Arch Gen Psychiatry 1994;51: $8-19$.

12. Magee WJ, Eaton WW, Wittchen HU, McGonagle KA, Kessler RC. Agoraphobia, simple phobia, and social phobia in the National Comorbidity Survey. Arch Gen Psychiatry 1996;53:159-168.

13. Regier DA, Boyd JH, Burke JD Jr, et al. One-month prevalence of mental disorders in the United States: based on five Epidemiologic Catchment area sites. Arch Gen Psychiatry 1988;45:977-986.

14. International Classification of Headache Disorders, $2^{\text {nd }}$ edition. Cephalalgia 2004;24(Suppl 1):S9-S160.

15. Stewart WF, Lipton RB, Dowson AJ, Sawyer J. Development and testing of the Migraine Disability Assessment (MIDAS) questionnaire to assess headache related disability. Neurology 2001;56:20-28.

16. First MB, Spitzer RL, Gibbon M, Williams JBW, Janet B. Structured clinical interview for DSM-IV Axis I disorders (SCID: clinical version users guide. Washington: APA, 1996.

17. Hamilton M. Rating scale for depression. J Neurol Neurosurg Psychiatry 1960;23:56-62.

18. Beck AT, Ward CH, Mendelson M, Mock J, Erbaugh G. An inventory for measuring depression. Arch Gen Psychiatry 1961;4:561-571.

19. Hamilton M. The assessment of anxiety states by rating. Br J Med Psychol 1959;32:50-55.

20. Spielberger CD, Gorsuch RI, Lushene RE (eds.). Manual for the statetrait anxiety inventory. Palo Alto: Consulting Psychologists Press, 1970.

21. Di Piero V, Bruti G, Venturi P, et al. Aminergic tone correlates of migraine and tension-type headache: a study using the tridimensional personality questionnaire. Headache 2001;41:63-71.

22. Nylander PO, Schlette P, Brandstrom S, et al, Adolfsson R. Migraine: temperament and character. J Psychiatr Res 1996;30:359-368.

23. Cloninger CR, Svrakic DM, Przybeck T. A psychobiological model of temperament and character. Arch Gen Psychiatry 1993;50:975-990.

24. Radat F, Sakh D, Lutz G, el Amrani M, Ferreri M, Bousser MG. Psychiatric comorbidity is related to headache induced by chronic substance use in migraineurs. Headache 1999;39:477-480.

25. Mercante JPP, Peres MFP, Guendler VZ, Corchs F, Bernik MA, Zukerman E. Cephalalgiaphobia: a new specific phobia of illness. Migrâneas e Cefaléias 2005;8:98. 